Trinity University

Digital Commons @ Trinity

Chemistry Faculty Research

Chemistry Department

2011

\title{
Access to NMR Spectroscopy for Two-Year College Students: The NMR Site at Trinity University
}

Nancy S. Mills

TrinityUniversity, nmills@trinity.edu

M. Shanklin

Follow this and additional works at: https://digitalcommons.trinity.edu/chem_faculty

Part of the Chemistry Commons

\section{Repository Citation}

Mills, N. S., \& Shanklin, M. (2011). Access to NMR spectroscopy for two-year college students: The NMR site at Trinity University. Journal of Chemical Education, 88(6), 835-839. doi:10.1021/ed100715y

This Article is brought to you for free and open access by the Chemistry Department at Digital Commons @ Trinity. It has been accepted for inclusion in Chemistry Faculty Research by an authorized administrator of Digital Commons @ Trinity. For more information, please contact jcostanz@trinity.edu. 


\title{
Access to NMR Spectroscopy for Two-Year College Students: The NMR Site at Trinity University
}

\author{
Nancy S. Mills ${ }^{*+}$ and Michael Shanklin ${ }^{\ddagger}$ \\ ${ }^{\dagger}$ Department of Chemistry, Trinity University, San Antonio, Texas 78212, United States \\ ${ }^{\ddagger}$ Department of Chemistry, Palo Alto College, San Antonio, Texas 78224, United States
}

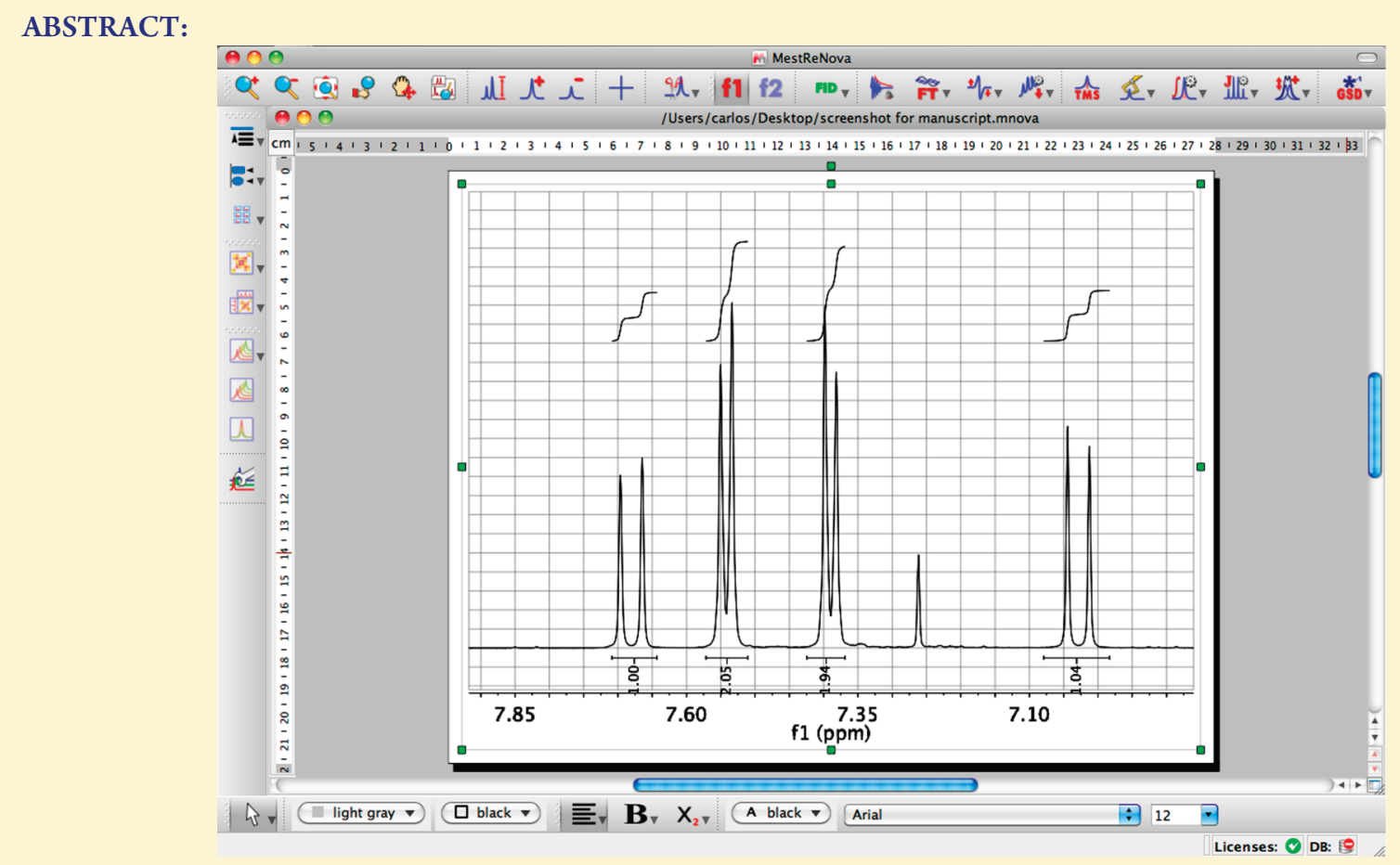

Students at two-year colleges and small four-year colleges have often obtained their exposure to NMR spectroscopy through "canned" spectra because the cost of an NMR spectrometer, particularly a high-field spectrometer, is prohibitive in these environments. This article describes the design of a NMR site at Trinity University in which spectral data from student samples from community colleges and several four-year colleges are obtained on a $300 \mathrm{MHz}$ NMR spectrometer. The unprocessed free induction decay (FID) is distributed to the students via the Internet and then processed by the students at their local institutions. The success of the NMR site at one two-year college, Palo Alto College, is described along with details of the experiments chosen for analysis. Two other two-year colleges, San Antonio College and Northwest Vista College, provide additional information about the effectiveness of the site.

KEYWORDS: Second-Year Undergraduate, Curriculum, Laboratory Instruction, Organic Chemistry, Computer-Based Learning, Hands-On Learning/Manipulatives, Laboratory Equipment/Apparatus, NMR Spectroscopy

$\mathrm{N}^{\prime}$ MR spectral analysis is recognized as one of the important analytical tools in chemistry. An NMR spectrometer is the only piece of instrumentation that is mandated for an approved chemistry program by the American Chemical Society. However, the high cost of a high-field Fourier transform (FT) NMR spectrometer, in terms of initial costs and maintenance costs for cryogens, puts the NMR spectrometer beyond the budget for many small schools, including two-year colleges. Even the cost of the Anasazi FT NMR spectrometer with a permanent magnet is beyond the budget of many schools.
Access to a regional site for NMR instrumentation would be a viable solution for many schools. One model for these sites is to provide the students with processed NMR data, including integration and expansion of appropriate regions. ${ }^{1}$ However, the educational value to students in the analysis of the data for the compound they create is greater than the real-world challenges of dealing with impurities in the sample such as unreacted starting

Published: $\quad$ March 25, 2011 


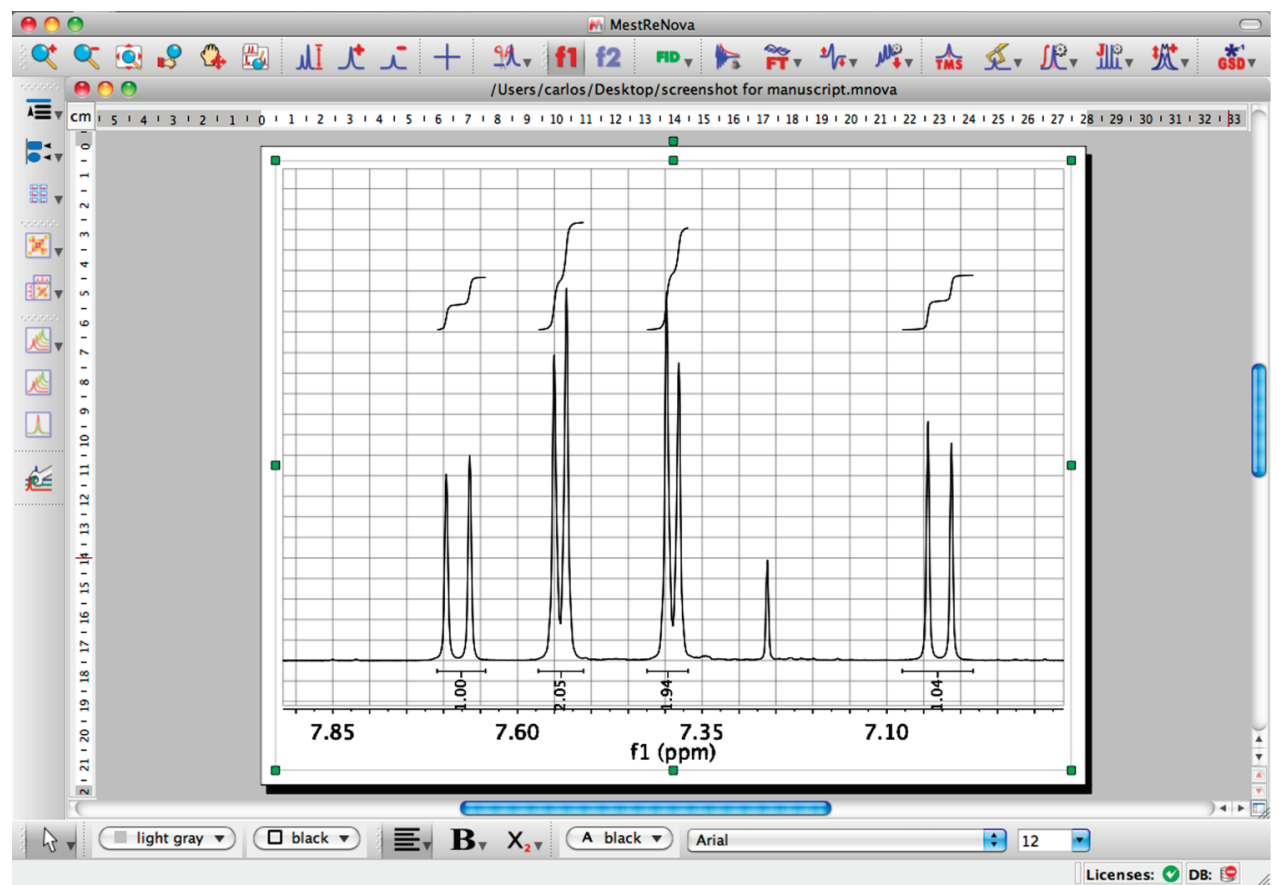

Figure 1. Active screen of Mnova NMR processing software.

material. The opportunity to process the data, to make the decisions of what peaks must be integrated and which regions must be expanded, is an equally important intellectual task. However, the requirement that students visit the regional site to process their data effectively limits access and ensures that most students will not be able to take full advantage of the site. This is particularly relevant for two-year colleges because over $40 \%$ of science and engineering graduates attend a two-year college at some point during their educational career. ${ }^{2}$ For these students to perform effectively when they transfer to a four-year college or university, they must have access to the same kinds of experiences the students at four-year colleges and universities have.

With support from the National Science Foundation and the Camille and Henry Dreyfus Foundation, we have created a virtual NMR site for students at five two-year colleges and two four-year institutions that allows the students to process the data from compounds they prepare at their home institution with free software as well as the commercial versions of the same software. The original users of the site were three two-year colleges in San Antonio, Palo Alto College, St. Philips College, and San Antonio College, who were then joined by Northwest Vista College as its science program developed. Schreiner University, a small fouryear college in Kerrville, Texas, has recently been joined by the University of the Incarnate Word in San Antonio, which uses the site for both teaching and research samples.

\section{HOW THE NMR SITE OPERATES}

The NMR site was designed to be self-supporting, within the following constraint: Trinity University pays for cryogens and maintenance of the Varian Mercury $300 \mathrm{MHz}$ spectrometer. Because Trinity University also has a Varian $500 \mathrm{MHz}$ NMR spectrometer, there are economies of scale for the liquid nitrogen and liquid helium fills. When the Mercury 300 NMR spectrometer is not being used by the NMR site, the students of the chemistry department at Trinity University have access to the spectrometer. In effect, the $300 \mathrm{MHz}$ NMR spectrometer can serve as a backup for the $500 \mathrm{MHz}$ spectrometer, so the cost of cryogens is a relatively small price to pay to avoid NMR downtime. This is a demonstration of the value of enlightened selfinterest; both Trinity University and the users of the site benefit from the Varian Mercury $300 \mathrm{MHz}$ spectrometer.

The users are charged a flat fee of $\$ 1.50$ per sample to pay for the cost of a student assistant to prepare and run the samples and for the cost of deuterated solvents and NMR tubes. This flat fee allows the users to budget for the cost of NMR analyses based on the number of students in class and to control the cost of their use of the site. When the site was first envisioned, the severe financial constraints of some of the community colleges appeared to be an impediment to their use of the site. In addition, some faculty at the smaller schools were reluctant to become involved in more sophisticated NMR analysis because it had been some time since they had been proficient in the analysis of the NMR spectra of real samples. Funding was obtained from the Dreyfus Foundation for the access of the two-year colleges to the site so that economics were not prohibiting the use of the site. Because the student assistants were efficient, the Dreyfus funding could be used for three years of support to the two-year colleges and to extend the support to four-year institutions that had no access to NMR instrumentation. Thus, the faculty at these schools were able to use the NMR site at no cost and to develop an understanding of their use patterns so that they could estimate the cost of using the site when the Dreyfus grant expired.

The discomfort of some of the community college faculty with the analysis of NMR spectra was another problem. In the summer following the first year of operation, a workshop was held to identify experiments that were particularly appropriate to product analysis by NMR spectroscopy. In the summer following the second year of operation, a workshop was held to improve the proficiency of the community college faculty in the analysis of NMR spectra. The workshop used two tools: NMRSolitare and 
NMR Mosaic. NMRSolitare is a tutorial that provides students an opportunity to work on spectral analysis on their own as well as an archive of NMR spectra that can be obtained in PDF form. ${ }^{3}$ NMR Mosaic ${ }^{4}$ is a puzzle-based guide to NMR analysis which helps students understand how to use the information in an NMR spectrum to determine how different parts of the molecule are connected.

The NMR samples are brought to Trinity University, ideally with sufficient advance warning so that the student assistant can plan for their analysis. After the student assistant runs the samples, he or she notifies the NMR site coordinator, who transfers the files from the Dell (Linux) Computer that controls the NMR spectrometer to a PC, where each student's file is compressed and transferred to the Web. A link is made from the NMR Web site ${ }^{5}$ to a folder for each participating institution and from there to a folder for each experiment and to the compressed file for each student. The student can then transfer the file to a personal computer, unzip the file, and process it using free software. The Dreyfus grant allowed the purchase of a perpetual license for the commercial version of the software for the institutions using the site. Alternatively, faculty can transfer the files to a computer lab, where students can work up the data.

The program used for the data process is MestReC, which was created by Mestrelab. At the time that the NMR site was started, the program could be downloaded for free, allowing all students to process data on their home computers. After several years, the MestReC developers decided to provide a commercial product, as well as a free download of an older version of the program. ${ }^{6}$ The free program is a bare-bones program that only runs on PCs. The most recent version of the commercial software is Mnova. ${ }^{7}$ It is a multiplatform program, running on PC, Mac, and Linux computers, and it supports all major NMR vendor formats. The software is controlled by icons; see the menu bar at the top of Figure 1. The icons are intuitive: referencing occurs via the icon with "TMS", integration via the $\int$ icon, change in the size of the spectra with + or -, and so forth. As you "mouse over" an icon, the name of the icon becomes visible. The software allows $1 \mathrm{D}$ and $2 \mathrm{D}$ processing and spectral simulation. The students at Trinity University have found the new version to be robust and easy to use; the program is used for publication quality spectra. The developers of Mnova have also been responsive to users from undergraduate institutions. Recently, the developers of Mnova substantially reduced the price of a perpetual site license for unlimited users to process both $1 \mathrm{D}$ and $2 \mathrm{D}$ NMR spectra. ${ }^{8}$

\section{NMR SPECTROSCOPY AT SMALLER INSTITUTIONS}

Palo Alto College is one of six two-year colleges that make up the Alamo Community College District. Similar to most twoyear colleges, Palo Alto College has a limited budget for science and lacks the ability to purchase and maintain many of the major scientific instruments such as NMR needed in a modern chemistry laboratory program. Since 2002, Palo Alto College and several other two-year colleges have participated in the NSFfunded NMR site housed at Trinity University. The cost of using the site is low and the convenience of having the free induction decay (FID) data placed on the Web to be processed locally results in an excellent learning experience.

Before Palo Alto College began using the regional NMR site, spectroscopy was taught as a single lab exercise in the spring semester. This laboratory exercise consisted of the students interpreting spectral data of known compounds taken from
Spectrometric Identification of Organic Compounds by Silverstein, et al. ${ }^{9}$ Although this exercise supported the lecture section on spectroscopy, it was a one-time experience with the students never able to see how spectroscopy related to their own lab work. This brief exposure to spectroscopy frustrated students in both the lecture and laboratory portion of the course. Grades on quizzes and exam questions in spectroscopy were often among the lowest grades in the semester. Ready access to an NMR spectrometer allowed the use of a different approach to teaching NMR spectroscopy. Instead of teaching instrumentation as a single stand-alone lab, NMR and other spectral techniques are now integrated into many of the labs taught at Palo Alto College. This approach has improved learning by allowing the students multiple exposures to the topic of spectroscopy over the period of two semesters and has led to a better understanding of how spectroscopy is used in the academic or industrial laboratory.

Students at Palo Alto College are introduced to spectroscopy during the middle of the first semester as a method for the analysis of a primary halide, usually 1-bromobutane, synthesized from 1-butanol. ${ }^{10}$ In this lab, students are introduced to the concepts of chemical shift and simple coupling. The more theoretical aspects of NMR spectroscopy are left for later treatment. Students are also taught the basics of downloading their spectra and working up the raw data they get back from Trinity University. It was originally hoped that the students could download and work up their own spectra, but over the years, it was discovered that many of the students at Palo Alto College lacked the computer skills necessary to perform this task. Some of the better students are able to download their spectra and even download the free, older copy of the Mestrelab software or, with a little help, use copies of the Mestrelab software available in our science study center to work up their NMR spectra. However, many students unfortunately lack the computer skills needed to process the data independently. It is often necessary to process the data for these students so that they can complete the primary objective of the project, learning how to interpret spectra. Once the students use chemical shifts and first-order coupling information to help determine the structure of an organic compound they already know, they are ready in a second laboratory exercise to use NMR and IR spectra to help them in determining the structure of an unknown organic compound.

During the second semester, carbon-13 spectroscopy is introduced by studying the ${ }^{13} \mathrm{C}$ spectra of highly symmetrical 2,5 di-tert-butyl-1,4-dimethoxybenzene synthesized by a Friedel-Crafts reaction of 1,4-dimethoxybenzene and 2-methyl-2propanol. ${ }^{10}$ Finally, the product of a Horner-Emmons modified Wittig reaction, of methyl (E)-4-methoxycinnamate ${ }^{10}$ is used to demonstrate the relationship between coupling constants and dihedral angles in a molecule. During the second semester, many of the theoretical concepts behind NMR and other spectral techniques are introduced in lecture.

On the basis of the grades of quizzes in spectroscopy given every spring semester, regular access to an NMR spectrometer has improved student understanding of the basics of spectroscopy. The average grades in their spectroscopy quiz have gone from $59 \%$ to $83 \%$ after the regular use of spectroscopy in organic lab was introduced. The process of accessing NMR data is relatively easy and in most instances data is available for samples within a week or less. This modest delay is more than acceptable for a two-year college. Using the Web as a delivery vehicle has worked well for both faculty and students. The price of the Mestrelab software is reasonable, 2,000 Euros for a perpetual site 
license, and copies of earlier software are available for free. The purchased software is available in Windows, Mac, and Linux versions, is menu driven, and easy to use. The use of a regional NMR center has been a cost-effective and easy method to improve the learning of NMR spectroscopy at Palo Alto College.

Faculty at San Antonio College have also valued the use of the NMR site. Prior to its creation, their students had no access to NMR spectra for samples prepared in class; now the students have learned to analyze NMR spectra of practically every compound they prepare in lab. Because the college has moved to microscale experiments, NMR data are particularly important in the student's appreciation of the laboratory. As one of the chemistry professors, Krishnan Madappat, said, "The NMR spectra we did with Trinity was one of the best parts of our CHEM 2225 course. Our preparations in this course are microscale. We could not have done them without NMR spectroscopy."

Students at Northwest Vista College also benefited from their exposure to "hands-on" NMR spectroscopy. Prakash Nair, chair of the department, felt that the students understood NMR spectroscopy better when they were working with spectra of compounds that they had prepared in lab and that they were better prepared for work in industry because they had an appreciation of the importance of sample contamination. $\mathrm{He}$ also felt that they were better prepared for entrance examinations to medical school and pharmacy school. Students who had participated in the NMR site also did significantly better on the NMR portions of exams than students who had only taken the lecture portion of the course.

\section{- SUGGESTIONS FOR OTHERS PLANNING AN NMR SITE}

If institutions are considering developing an NMR site, we have suggestions from our experience. First, it is important to purchase an instrument with gradient (automatic) shimming capabilities; for most instruments this is now standard. To provide the spectra efficiently and economically, the student assistants cannot afford to spend much time shimming the instrument. In addition, gradient shimming allows student assistants with a range of NMR expertise to provide high quality spectra. Second, many institutions will assume that a sample changer is necessary for effective processing of multiple samples. Information should be sought about the durability of the sample changer from users because different types of sample changers can be problematic. Third, it may be considered advantageous to operate the NMR remotely, and the major NMR manufacturers, Varian (Agilent), Bruker, and JEOL, offer such software. However, the cost of a Linux computer, in the case of Varian software, and the expectation of additional expertise on the part of the faculty was not attractive to the majority of faculty at the two-year institutions involved in the Trinity University site. Because the samples still need to be brought to Trinity University, there is no real time saving for the users. The original intent was to have the student assistant transfer the spectra from the Sun computer to the PC, then to the Web, and create the links to the Web, but this proved to be challenging for some of the students, so this is now done entirely by the NMR site administrator, which is less than optimal but allows some quality control.

Fourth, the success for the two- and four-year institutions using the site depends almost entirely on the experience of the faculty at those schools with NMR spectroscopy. In particular faculty who have been out of graduate school for a reasonable period of time are less comfortable with processing and interpreting NMR spectra, particularly spectra that contain impurities, which are common in student samples. The NMR site administrator can inspect the data before it is transferred to the Web and report to the faculty on issues that might affect the successful interpretation of data, such as the absence of a TMS peak, the larger than usual peak for water, or a larger than usual peak for the residual $\mathrm{CHCl}_{3}$ in a dilute sample.

Finally, economical access to NMR processing software can be a challenge. The commercial version of the Mestrelab software, Mnova, is easy to use, but it is not free. There are versions of processing software, such as iNMR ${ }^{11}$ for the Mac computer that have student versions that are cheaper, and open-source programs such as $\mathrm{rNMR}^{12}$ that are free. Acorn $\mathrm{NMR}^{13}$ has complementary student licenses for Mac and PC operating systems, but prices for a faculty copy range from $\$ 100$ for $1 D$ processing without technical support to $\$ 1000$ for advanced 2D and 1D processing and technical support. SpinWorks ${ }^{14}$ is a free program that runs with the PC operating system. We do not have any experience with any of these programs.

\section{CONCLUSIONS}

The NMR site has been a satisfactory arrangement for the institutions providing samples and for Trinity University. We have developed closer relationships with each other. Several of the institutions bring their students to Trinity University for a tour of the instrumental facilities and we encourage students in those classes to apply for the summer research program in chemistry at Trinity University. The NMR site was designed to be self-sustaining after the cessation of the Dreyfus grant. The site survived the end of the funding from the Dreyfus grant and also the absence of the original NMR site administrator when she was on academic leave. Another faculty member was able to serve as site administrator and the use of the site continued unabated.

\section{AUTHOR INFORMATION}

\section{Corresponding Author}

*E-mail: nmills@trinity.edu.

\section{ACKNOWLEDGMENT}

We would like to thank the National Science Foundation (DUE 0126497) and the Camille and Henry Dreyfus Foundation (SG-02-053) for the funding for the Varian Mercury Plus $300 \mathrm{MHz}$ NMR spectrometer. Krishnan Madappat (San Antonio College) and Prakash Nair (Northwest Vista College) played an important role in working out the details of the use of the site.

\section{REFERENCES}

(1) Strange de Soria, L. E.; Soria, J. J.; Silverstein, H. In 231st ACS National Meeting; Atlanta, GA, March 26-30, 2006; p 1364.

(2) Tsapogas, J. The Role of Community Colleges in the Education of Recent Science and Engineering Graduates. NSF InfoBrief [Online Early Access]. Published Online: 2004. http://www.nsf.gov/statistics/ infbrief/nsf04315/ (accessed Feb 2011).

(3) For information about the NMRSolitare tutorial contact benshoulders@mail.utexas.edu.

(4) McClusky, J. V. J. Chem. Educ. 2007, 84, 983.

(5) MestReC v 2.3. http://mestrelab.com/software/mestrec/ mestrec-2-3/ (accessed Feb 2011). 
(6) The NMR Web site. http://www.trinity.edu/departments/ chemistry/NMRSite/index.html (accessed Feb 2011).

(7) Mestrec Home Page. http://mestrelab.com (accessed Feb 2011).

(8) Mnova for Undergraduates. http://mestrelab.com/undergraduate/ (accessed Feb 2011).

(9) Silverstein, R. M.; Webster, F. X.; Kiemle, D. Spectrophotometric Identification of Organic Compounds, 7th ed.; John Wiley: Hoboken, NJ, 2005.

(10) Mohrig, J. R.; Hammond, C. N.; Schatz, P. F.; Morrill, T. Modern Projects and Experiments in Organic Chemistry, 2nd ed.; W. H. Freeman: New York, 2003.

(11) iNMR Home Page. http://www.inmr.net (accessed Feb 2011).

(12) rNMR Home Page. http://rnmr.nmrfam.wisc.edu (accessed Feb 2011).

(13) Acorn NMR Home Page. http://www.acornnmr.com/ (accessed Feb 2011).

(14) SpinWorks Home Page. http://www.umanitoba.ca/chemistry/ nmr/spinworks/ (accessed Feb 2011). 